\title{
FATIGUE LIFE EVALUATION OF IN-SERVICE STEEL BRIDGES BY USING BI-LINEAR S-N CURVES
}

\author{
Chun-sheng Wang ${ }^{1, *}$, Ben T. Yen ${ }^{2}$, Hai-ting $\mathrm{Li}^{3}$ and Lan Duan ${ }^{1}$ \\ ${ }^{1}$ Engineering Research Center for Large Highway Structure Safety of Ministry of Education, \\ College of Highways, Chang'an University, Xi'an, Shaanxi Province, China \\ ${ }^{2}$ Department of Civil and Environmental Engineering, Lehigh University, Bethlehem, PA 18015-4729, USA \\ ${ }^{3}$ Department of Civil Engineering, The University of Hong Kong , Hong Kong, China \\ *(Corresponding author: E-mail: wcs2000wcs@163.com)
}

\begin{abstract}
The in-service steel bridges are often required to carry increasing volume of traffic and heavier trucks or freight trains. More attention should be paid to possible fatigue damages of such structures. It has been reported that for many structure details with an equivalent stress range below the constant amplitude fatigue limit (CAFL) and free of fatigue cracks, calculations show that the remaining fatigue life has been exhausted. This condition indicates that it could be too conservative to predict the remaining fatigue life of in-service steel bridges by utilizing the equivalent constant amplitude stress ranges with the direct extension of S-N curves of AASHTO specifications with a slope of -3 to below the CAFL. This over-prediction of fatigue damage may lead to unnecessary rehabilitation and maintenance actions. For a better fatigue life evaluation and prediction, a set of bi-linear S-N curves with a break at the CAFL for the AASHTO fatigue strength categories and with a slope of -4 below, has been proposed for fatigue life evaluation of in-service structures. This paper applies the concept of the equivalent constant amplitude stress range for bi-linear curves to AASHTO specifications and Eurocode. Cases of fatigue evaluation of in-service steel bridge components are studied by correlating the field-measured live-load stresses with the bi-linear S-N curves. Comparative results from the bi-linear S-N curve approach, the current AASHTO specifications and Eurocode approach are presented.
\end{abstract}

Keywords: Steel bridges, Fatigue life evaluation, Bi-linear S-N curve, Constant amplitude fatigue limit, Equivalent stress range

DOI: $10.18057 /$ IJASC.2015.11.3.2

\section{INTRODUCTION}

For many in-service steel bridges, fatigue is a primary safety concern and each structural detail of a steel bridge has its evaluated fatigue strength according to the current design codes and specifications. The fatigue strength categories (S-N curves) define the relationship between the applied primary stress range (live-load stress range) of constant amplitude and the number of stress cycles when fatigue damage is expected.

The current procedure for predicting the remaining fatigue life of steel bridges by AASHTO specifications [1] utilizes an equivalent constant amplitude stress ranges $\left(S_{\mathrm{re}}\right)$ with the direct extension of the S-N curves of a single slope of -3 to below the constant amplitude fatigue limit (CAFL) for the different detail categories. In order to calculate the $S_{\text {re, }}$ a live load stress range spectrum or histogram for the structural detail should be developed to correlate with the governing $\mathrm{S}-\mathrm{N}$ curve [2]. The fatigue life evaluated by this approach is generally adequate for bridge safety management [3]. Yet this approach was found to be conservative, often resulting in over-prediction of fatigue damage and may lead to unnecessary rehabilitation or maintenance actions. A number of details have been found to be free of cracks although the calculated remaining fatigue life by the current procedure showed that the details should be suffered from cracks [4]. For this reason, the direct extension of S-N curves from above to below the CAFL was examined analytically [5]. The result is a set of bi-linear S-N curves with a break at the CAFL and a slope of -4 below for the 
fatigue strength categories in AASHTO. The utilization of bi-linear S-N curves is being considered by bridge engineers [6].

The fatigue life evaluation of in-service steel bridges should be conducted based on the performance of the bridge structure under actual live loads. This is because the assumptions made on service loads during the design stage usually do not provide sufficiently accurate representation of the actual live load history. Even more importance is the fact that almost all connections and joints of bridge components do not behave exactly in the service state as considered in design according to the strength state. The behavior of a bridge structure under service loads at specific positions of these loads on the bridge can be analyzed using finite element models. However, the positions of the trucks, the size and weight of these truck loads are various. Therefore, direct monitoring of field-measured live-load stresses at fatigue-prone structural details is best suited for the fatigue life evaluation.

\section{FATIGUE LIFE EVALUATION BY USING BI-LINEAR S-N CURVES}

\subsection{The Concept of Bi-linear S-N Curves}

The AASHTO S-N curves are typically established based on the results of numerous experimental studies and the values of CAFLs are associated with the stress intensity factor range threshold, $\Delta K_{\mathrm{th}}[7]$. The stress intensity factor range can be expressed as Eq. (1).

$\Delta K=\Delta \sigma \cdot \sqrt{\pi a} \cdot Y$

And it follows as Eq. (2).

$\Delta K_{\mathrm{th}}=C A F L \cdot \sqrt{\pi a_{\mathrm{i}}} \cdot Y$

Where $\Delta \sigma$ is the applied stress-range; $a$ is the size of fatigue crack; $a_{\mathrm{i}}$ is the hypothetical initial value of crack size associated with $\Delta K_{\text {th }}$; and $Y$ is a non-dimensional function of the geometry including various factors such as finite width factor, non-uniform stresses factor, free surface effect factor and crack shape factor.

Stress range cycles in a spectrum with amplitudes higher than the CAFL would cause micro-scaled increase of the crack to greater than $a_{\mathrm{i}}$ and, as indicated in Eq. 2 , the value of CAFL would decrease as the crack size increases because the value of $\Delta K_{\text {th }}$ remains constant. It is concluded that this condition would subsequently allow slightly lower magnitude stress-range cycles in a spectrum to contribute to the crack growth [5, 8-9].

By using this concept to examine the repeated cumulative damage of a few stress range histograms, Crudele \& Yen [5] analytically examined the extension of S-N curves below the CAFL of four different AASHTO categories (B, C, D, and E). They found that the computed fatigue lives above the CAFL agreed well with the fatigue lives associated with the AASHTO S-N curves for all categories and, however, fatigue lives below the CAFL have to be re-estimated. Results indicated that the average slope of extended lines of the fatigue strength categories is -4 below the CAFL. This slope is recommended for use. Figure 1 shows the derived bi-linear S-N curves for all AASHTO categories [6]. The S-N curve of structural detail Category $\mathrm{C}^{\prime}$ is shown in Figure 2 with some experimental data [10]. The result of Figure 2 provides confidence for the application of bi-linear S-N curves. 


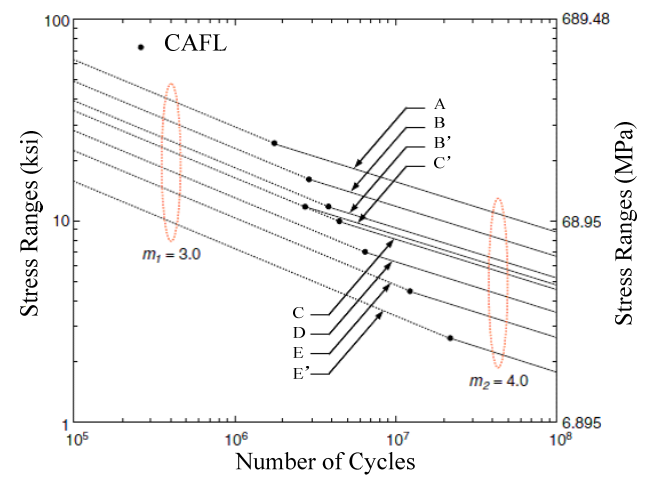

Figure 1. Bi-linear S-N Curves for All Fatigue Categories [6]

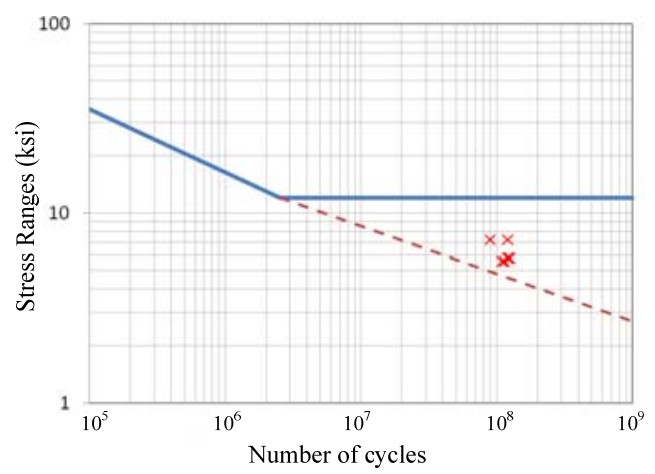

Figure 2. Bi-linear S-N Curves for Category $C^{\prime} \quad[10]$

It is worth noticing that Europe has adopted a set of tri-linear S-N curves with a slope of $m$ when stress ranges are above CAFL, and the second slope below CAFL is suggested as $2 m-1$ by Haibach [11-12], while $m=3$ is used in Eurocode 3[13] with a horizontal line after the cut-off limit at 100 million cycles, as shown in Figure 3. For other details, the first slope was also found to be $m_{1}=4$ and the second slope is $m_{2}=2 m_{1}-1=7$ for riveted and bolted details.

\subsection{Evaluation approach}

According to Palmgren-Miner linear damage hypothesis, Eq. (3) indicates fatigue failure.

$D=\sum_{i} \frac{n_{i}}{N_{i}}=1$

Where $n_{i}$ is number of cycles accumulated at stress range level $i$, for which damage would occur when the stress is applied $N_{i}$ cycles; $D$ is the fraction of life consumed by exposure to the cycles at the different stress range levels.

For a bi-linear S-N curve with a break at the magnitude of stress range $K$ and the slopes of $m_{1}$ and $m_{2}$ above and below $K$, respectively, the application of Palmgren-Miner linear damage hypothesis shows in Eq. (4).

$D=\sum_{i} \frac{n_{i}}{N_{i}}+\sum_{j} \frac{n_{j}}{N_{j}}=1$ 
Where the subscripts $i$ and $j$ mean stress cycles above and below the break at $K$, respectively. Using the stipulation of equivalent stress range by Schilling et al. [14], Eq. (5) can be acquired.

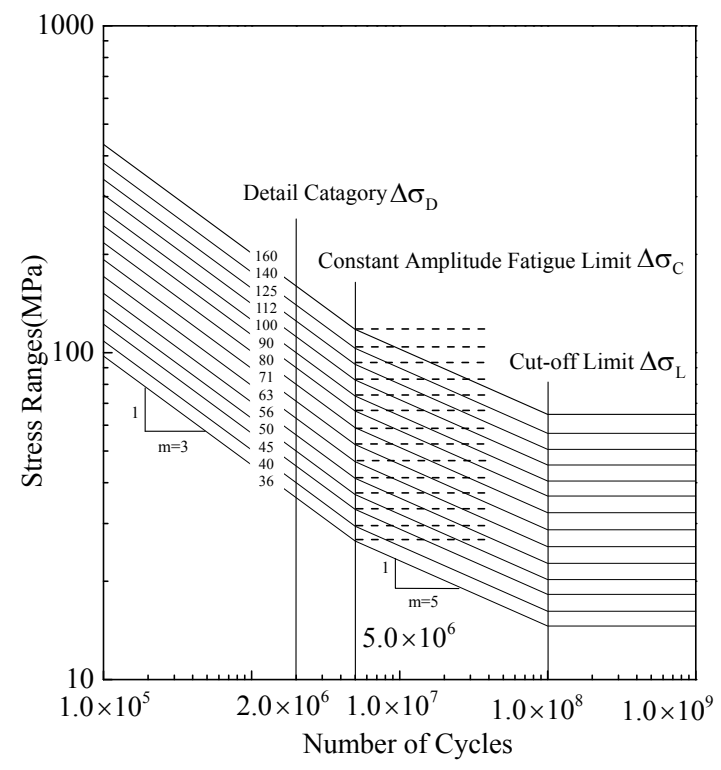

Figure 3. The Tri-linear S-N Curves in Eurocode 3 [13]

$D=\sum_{i} \frac{n_{i}}{N_{i}}+\sum_{j} \frac{n_{j}}{N_{j}}=\frac{\sum_{i, j}\left(n_{i}+n_{j}\right)}{N_{\mathrm{e}}}=1$

The symbol $N_{\mathrm{e}}$ is the calculated fatigue life using the equivalent constant amplitude stress range $S_{\mathrm{re}}$. The sum of all stress cycles is $\sum_{i, j}\left(n_{i}+n_{j}\right)=N$ and the equations for the two segments of the S-N curves are shown in Eq. (6).

$N_{i}=A_{m_{1}} \cdot S_{i}^{-m_{1}}$ and $N_{j}=A_{m_{2}} \cdot S_{j}^{-m_{2}}$

Corresponding to $N_{\mathrm{e}}$ for single-slope S-N curves, the equations of the segments of the bi-linear one are shown in Eq. (7).

$N_{\mathrm{e}}= \begin{cases}A_{m_{1}} \cdot S_{\text {rem } m_{1} m_{2}}^{-m_{1}} & \text { for } S_{\text {rem } m_{1} m_{2}} \geq K \\ A_{m_{2}} \cdot S_{\text {rem } m_{1} m_{2}}^{-m_{2}} & \text { for } S_{\text {rem } m_{2}}<K\end{cases}$

$S_{\text {rem } m_{2} m_{2}}$ with a double subscripts, $m_{1}$ and $m_{2}$, is the equivalent constant amplitude stress range for bi-linear S-N curves. By substituting Eq. (6) and Eq. (7) into Eq. (5), and solving for $S_{\text {rem }_{1} m_{2}}$, Eq. (8) can be acquired. 


$$
S_{\mathrm{rem}_{1} m_{2}}= \begin{cases}\left(\sum_{i} \frac{n_{i}}{N} \cdot S_{i}^{m_{1}}+\frac{A_{m_{1}}}{A_{m_{2}}} \sum_{j} \frac{n_{j}}{N} \cdot S_{j}^{m_{2}}\right)^{1 / m_{1}} & \text { for } S_{\text {rem }_{1} m_{2}} \geq K \\ \left(\frac{A_{m_{1}}}{A_{m_{2}}} \sum_{i} \frac{n_{i}}{N} \cdot S_{i}^{m_{1}}+\sum_{j} \frac{n_{j}}{N} \cdot S_{j}^{m_{2}}\right)^{1 / m_{2}} & \text { for } S_{{\text {rem } m_{1} m_{2}}_{2}<K}<\end{cases}
$$

By using the stress cycle, the coefficients ratio, $N_{k}$, in the Eq. 8 can be determined at the break of the S-N curve, shown in Eq. (9).

$$
N_{k}=A_{m_{1}} K^{-m_{1}}=A_{m_{2}} K^{-m_{2}}
$$

This leads to Eq. (10).

$$
\frac{A_{m_{1}}}{A_{m_{2}}}=K^{m_{1}-m_{2}}, \frac{A_{m_{2}}}{A_{m_{1}}}=K^{m_{2}-m_{1}}
$$

In this way, $S_{\text {rem } m_{2} m_{2}}$ can be determined by Eq. (11).

$$
S_{\text {rem } m_{1} m_{2}}= \begin{cases}\left(\sum_{i} \frac{n_{i}}{N} \cdot S_{i}^{m_{1}}+K^{m_{1}-m_{2}} \sum_{j} \frac{n_{j}}{N} \cdot S_{j}^{m_{2}}\right)^{1 / m_{1}} & \text { for } S_{\text {rem } m_{1} m_{2}} \geq K \\ \left(K^{m_{2}-m_{1}} \sum_{i} \frac{n_{i}}{N} \cdot S_{i}^{m_{1}}+\sum_{j} \frac{n_{j}}{N} \cdot S_{j}^{m_{2}}\right)^{1 / m_{2}} & \text { for } S_{{\text {rem } m_{1} m_{2}}_{2}}<K\end{cases}
$$

Specifically, for a bi-linear S-N curve with the break at the CAFL (i.e. $\mathrm{K}=\mathrm{CAFL}$ ) and the slopes above and below CAFL of the S-N curve are $m_{1}=3$ and $m_{2}=4$, respectively. The equations for the equivalent constant amplitude stress ranges $S_{\text {re34 }}$ are expressed by Eq. (12).

$$
S_{\mathrm{re} 34}= \begin{cases}\left(\sum_{i} \frac{n_{i}}{N} \cdot S_{i}^{3}+\frac{\sum_{j} \frac{n_{j}}{N} \cdot S_{j}^{4}}{C A F L}\right)^{1 / 3} & \text { for } S_{\mathrm{re} 34} \geq C A F L \\ \left(C A F L \cdot \sum_{i} \frac{n_{i}}{N} \cdot S_{i}^{3}+\sum_{j} \frac{n_{j}}{N} \cdot S_{j}^{4}\right)^{1 / 4} & \text { for } S_{\mathrm{re} 34}<C A F L\end{cases}
$$


The corresponding equations for fatigue life estimation are Eq. (13).

$N_{34}= \begin{cases}A_{3} \cdot S_{\mathrm{re} 34}^{-3} & \text { for } S_{\mathrm{re} 34} \geq C A F L \\ A_{3} \cdot C A F L \cdot S_{\mathrm{re} 34}^{-4} & \text { for } S_{\mathrm{re} 34}<C A F L\end{cases}$

For the categories, the values of $A_{3}$ and CAFL can be found in the AASHTO specifications.

In ordinary cases, when evaluating the fatigue life of an in-service steel bridge, only a small percentage of stress ranges in a stress histogram are above the CAFL and the computed $S_{\text {re } 34}$ would be below the CAFL. Consequently, the segment below of the CAFL with a slope of -4 could conservatively be used from Eq. (14) and Eq. (15) [15].

$$
\begin{aligned}
& S_{\mathrm{re} 4}=\left(\sum_{i} \frac{n_{i}}{N} \cdot S_{i}^{4}\right)^{1 / 4} \\
& N_{4}=A_{3} \cdot C A F L \cdot S_{\mathrm{re} 4}^{-4}
\end{aligned}
$$

\section{APPLICATIONS}

\subsection{Wei River Railway Bridge}

A railway steel bridge, recorded as No.1 Wei River Railway Bridge and shown in Figure 4, was monitored using field-measurement of live-load stresses at several fatigue-prone structural details. The bridge, built in 1982, is a welded and bolted steel girder bridge with twelve simply supported spans of $26.15 \mathrm{~m}$ [16]. The monitoring of dynamic stresses under traffic conditions, detailed inspection for crack detection and examination of service traffic were conducted in the years of 2006, 2008 and 2011, for three short time periods.

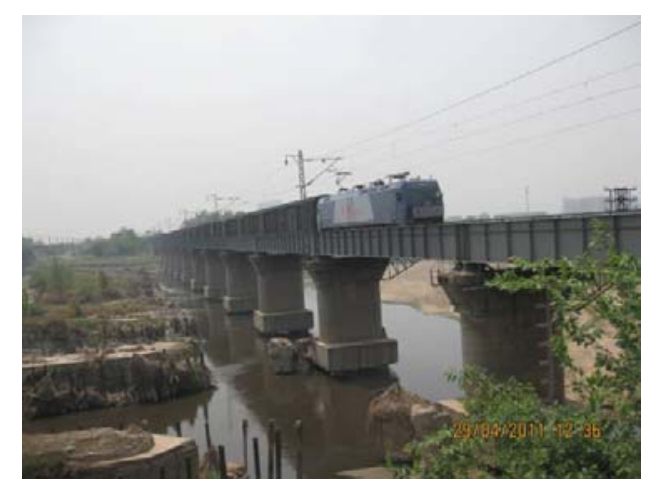

Figure 4. No.1 Wei River Railway Bridge

\subsubsection{Acquisition of stress range spectra}

The photographs of two retrofit gusset plates which were studied are shown in Figure 5. These are 10UPU and 10DPU at the bottom flange connection between the end-panel lateral bracing frames and the main girders. The dynamic stresses in 24 hours and the type of trains, locomotives, carriage number and speed were recorded. The rain-flow counting procedure was used to count the different stress ranges. The live load stress range spectra at strain gauges 10UPU-1 and 10DPU-1 are given in Figure 6. As detail of Category B, the maximum stress range at 10UPU-1 is 64MPa and is below 
the CAFL of $110 \mathrm{MPa}$. However, at 10DPU-1 the maximum stress range is $183 \mathrm{MPa}$ and 60 cycles are above the CAFL.

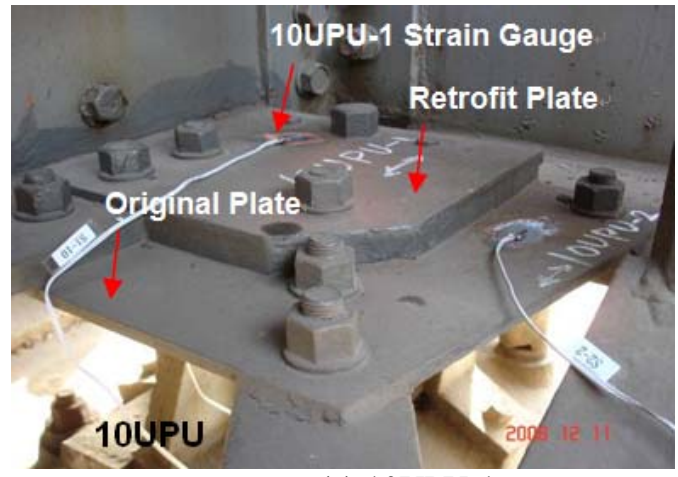

(a) 10UPU-1

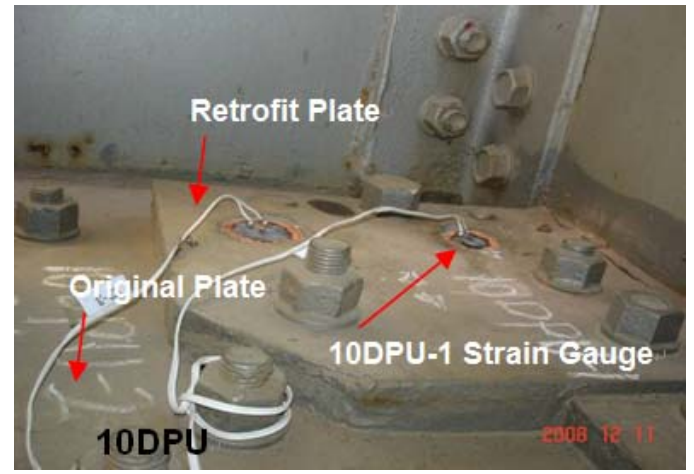

(b) 10DPU-1

Figure 5. Strain Measure Points of No.1 Wei River Railway Bridge

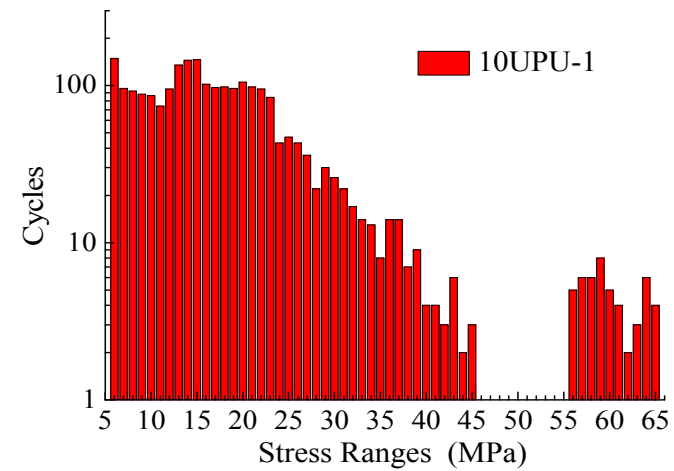

(a) Stress Spectrum of 10UPU-1

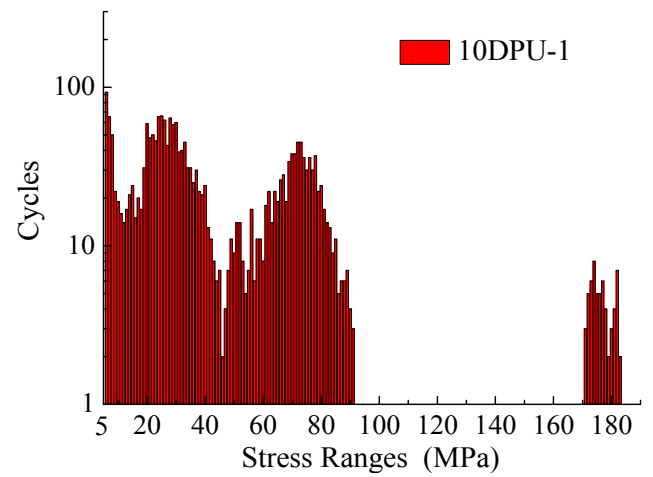

(b) Stress Spectrum of 10DPU-1

Figure 6. Recorded Stress Spectra of 10UPU-1 and 10DPU-1

\subsubsection{Fatigue life evaluation}

The equivalent constant amplitude stress ranges, $S_{\text {re34 }}$ of spectra in Figure 6 are computed using Eq. 12 and Eq. 14 for $S_{\text {re } 34}$ and $S_{\text {re } 4}$, respectively. In addition, the current root-mean-cube (RMC) equivalent stress range in AASHTO specifications for fatigue life evaluation under variable amplitude stress ranges is computed for comparison by using Eq. (16) and Eq. (17).

$$
\begin{aligned}
& S_{\mathrm{re} 3}=\left(\sum_{i} \frac{n_{i}}{N} \cdot S_{i}^{3}\right)^{1 / 3} \\
& N_{3}=A_{3} \cdot S_{\mathrm{re}}^{-3}
\end{aligned}
$$

The corresponding estimated fatigue lives are listed in Table 1.

As indicated earlier, all the stress cycles at gauge 10UPU-1 are below the CAFL of category B, so the expected fatigue life is infinite. At gusset plate measure point 10DPU-1, the increases in estimated fatigue life between using a single-sloped S-N line and the bi-linear line are 4.0 and 4.6 million cycles. The ratio of the increased life is $21.9 \%$, and that of is $38.0 \%$. In addition, as illustrated in Table 1, when the majority of stress range cycles in the spectrum are below the CAFL, 
the estimated fatigue life by using a single S-N line of slope -4 below CAFL is very close to that by the bi-linear curve.

Table 1. Comparison of Estimated Fatigue Life

\begin{tabular}{ccccccc}
\hline \multirow{2}{*}{ Detail } & Category & $N_{3}$ & $N_{34}$ & $N_{4}$ & $\frac{N_{34}-N_{3}}{N_{3}}$ & $\frac{N_{34}-N_{4}}{N_{4}}$ \\
& & $(\mathrm{Mil})$ & $(\mathrm{Mil})$ & $(\mathrm{Mil})$ & - & - \\
\hline 10UPU-1 & $\mathrm{B}$ & Infinite & Infinite & Infinite & - & $38.0 \%$ \\
\hline
\end{tabular}

Other retrofitted details of categories C and D in Wei River Railway Bridge have also been evaluated using bi-linear S-N curves. The live load stress range spectra of two other structural details, 10UWI (Category C) and 12CBSD (Category D), are shown in Figure 7. The corresponding fatigue life evaluation results by using the AASHTO S-N curves and the bi-linear S-N curves are listed and compared in Table 2.

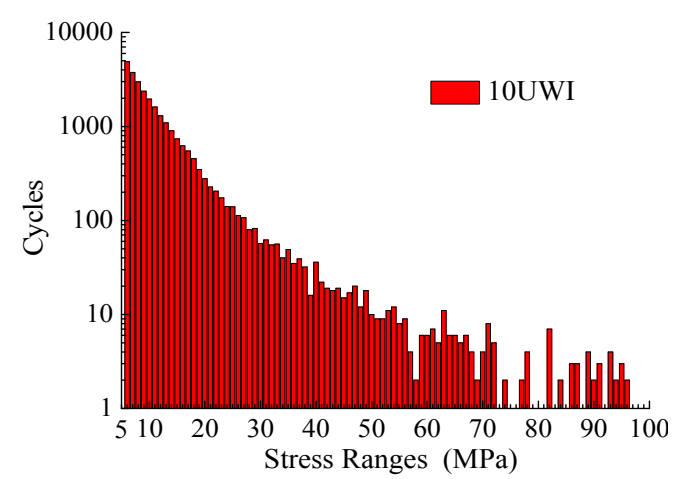

(a) Stress Spectrum of 10UWI

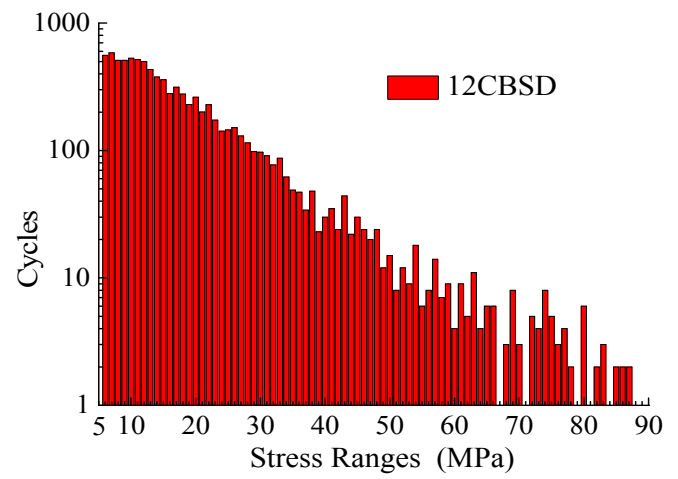

(b) Stress Spectrum of $12 \mathrm{CBSD}$

Figure 7. Recorded Stress Spectra of 10UWI and 12CBSD

Table 2. Comparison of Estimated Fatigue Life

\begin{tabular}{|c|c|c|c|c|c|c|}
\hline Detail & Category & $\begin{array}{c}N_{3} \\
\text { (Mil) }\end{array}$ & $\begin{array}{c}N_{34} \\
(\mathrm{Mil}) \\
\end{array}$ & $\begin{array}{c}N_{4} \\
\text { (Mil) } \\
\end{array}$ & $\frac{N_{34}-N_{3}}{N_{3}}$ & $\frac{N_{34}-N_{4}}{N_{4}}$ \\
\hline 10UWI & $\mathrm{C}$ & 17.5 & 22.3 & 20.1 & $27.4 \%$ & $10.9 \%$ \\
\hline $12 \mathrm{CBSD}$ & $\mathrm{D}$ & 15.7 & 18.7 & 15.2 & $19.1 \%$ & $23.0 \%$ \\
\hline
\end{tabular}

From the results listed in Table 2, the evaluation based on bi-linear fatigue S-N curves with different slopes above and below the CAFL always predicts a longer fatigue life compared to that based on the single slope AASHTO S-N curves. The increase of estimated fatigue life can be quite significant. For the category $\mathrm{C}$ detail $10 \mathrm{UWI}$, the increase is 4.8 million cycles and the increased life ratio is $27.4 \%$. For the category $\mathrm{D}$ detail $12 \mathrm{CBSD}$, the increase is 3.0 million cycles and the increased life ratio is $19.1 \%$. For the 3 details listed in Tables 1 and 2, using bi-linear fatigue S-N curves compared to using the current AASHTO S-N curves results in at least a $19.1 \%$ increase of fatigue life. This suggests that it may be unnecessary to take rehabilitation action at some structural details, which could reduce the maintenance fee and life-cycle cost.

To examine the evaluation of fatigue life by the Eurocode $\mathrm{S}-\mathrm{N}$ curves, the fatigue life of the 3 details are calculated according to the procedure of Eurocode 3. The procedure of using RMC as the equivalent constant amplitude stress range is in essence the extension of slope -3 down to below 
the CAFL without considering the portion of the S-N curves with a slope of -5. And ignoring of all stress data below the horizontal cut-off limit means ignoring the contribution of those stress cycles to the growth of the fatigue crack. Consequently, it is expected that the estimated fatigue life by using the suggested procedure for the bi-linear Eurocode S-N curves is longer than that by the suggested bi-linear S-N curves for AASHTO. This is the case for all four details of the Wei River Railway Bridge as listed in Table 3.

It is suggested that a set of equations for the bi-linear S-N curves with the break at the CAFL be used for the Eurocode 3. The slopes above and below CAFL of S-N curves are -3 and -5 , respectively. From Eq. (11), the equivalent constant amplitude stress range $S_{\text {re35 }}$ can be expressed as Eq. (18).

$$
S_{\mathrm{re} 35}= \begin{cases}{\left[\sum_{i} \frac{n_{i}}{N} \cdot S_{i}^{3}+\frac{\sum_{j} \frac{n_{j}}{N} \cdot S_{j}^{5}}{(C A F L)^{2}}\right)^{1 / 3}} & \text { for } S_{\mathrm{re} 35} \geq C A F L \\ {\left[(C A F L)^{2} \cdot \sum_{i} \frac{n_{i}}{N} \cdot S_{i}^{3}+\sum_{j} \frac{n_{j}}{N} \cdot S_{j}^{5}\right]^{1 / 5}} & \text { for } S_{\mathrm{re} 35}<C A F L\end{cases}
$$

The corresponding equations for the estimation of fatigue life is Eq. (19).

$N_{35}= \begin{cases}A_{3} \cdot S_{\mathrm{re} 35}^{-3} & \text { for } S_{\mathrm{re} 35} \geq C A F L \\ A_{3} \cdot(C A F L)^{2} \cdot S_{\mathrm{re} 35}^{-5} & \text { for } S_{\mathrm{re} 35}<C A F L\end{cases}$

In most cases, when evaluating the fatigue life for in-service steel bridges, only a small percentage of stress ranges are above the CAFL and the computed $S_{\text {re35 }}$ would be below the CAFL. Consequently, the segment below of the CAFL with a slope of -5 could conservatively be used from Eq. 20 and Eq. 21.

$$
\begin{aligned}
& S_{\text {res }}=\left(\sum_{i} \frac{n_{i}}{N} \cdot S_{i}^{5}\right)^{1 / 5} \\
& N_{5}=A_{3} \cdot(C A F L)^{2} \cdot S_{\text {re } 5}^{-5}
\end{aligned}
$$

The procedure of using the bi-linear line with slopes of -3 and -5 , and ignoring the damage contribution of stress ranges below the horizontal cut-off limits. Table 3 shows the comparison between the calculated fatigue lives. From Table 3, it is obvious that the estimated fatigue life by using bi-linear line with slopes of -3 and $-5\left(L_{35}\right)$ is close to Eurocode 3 approach $\left(L_{\text {euro }}\right)$, both of which are slightly longer than by using the suggested bi-linear S-N curves for AASHTO $\left(L_{34}\right)$.The suggested procedure of the bi-linear $L_{35}$ is less conservative in fatigue life evaluation compared to using the bi-linear S-N curves with the slopes of -3 and $-4\left(L_{34}\right)$ and the current AASHTO S-N curves. 
Table 3. Comparison of Estimated Fatigue Life

\begin{tabular}{|c|c|c|c|c|c|c|}
\hline Detail & Category & $\begin{array}{c}L_{35} \\
\text { (Year) } \\
\end{array}$ & $\begin{array}{c}L_{\text {euro }} \\
\text { (Year) }\end{array}$ & $\begin{array}{c}L_{34} \\
\text { (Year) }\end{array}$ & $\frac{L_{35}-L_{\text {euro }}}{L_{\text {euro }}}$ & $\frac{L_{35}-L_{34}}{L_{34}}$ \\
\hline 10DPU-1 & B & 92 & 88 & 80 & $4.5 \%$ & $15.0 \%$ \\
\hline 10UWI & $\mathrm{C}$ & 211 & 217 & 179 & $-2.8 \%$ & $17.9 \%$ \\
\hline $12 \mathrm{CBSD}$ & D & 85 & 93 & 75 & $-8.6 \%$ & $13.3 \%$ \\
\hline
\end{tabular}

\subsection{Wei River Freeway Bridge}

To further apply and analyze the bi-linear S-N curves for fatigue life evaluation for in-service bridges, a freeway bridge, named as Wei River Freeway Bridge shown in Figure 8, was monitored by field-measurement of live load stress at several fatigue-prone structural details in orthotropic steel bridge deck. Wei River Freeway Bridge, built in 2011, is a continuous concrete bridge as a whole while a $53.68 \mathrm{~m}$ steel girder is adopted at side span to optimize the overall structural behavior. Since there are many fatigue details in OSDs [17], a twelve-day dynamic stress monitoring under traffic conditions were conducted in 2013 to evaluate the fatigue performance of the structure.

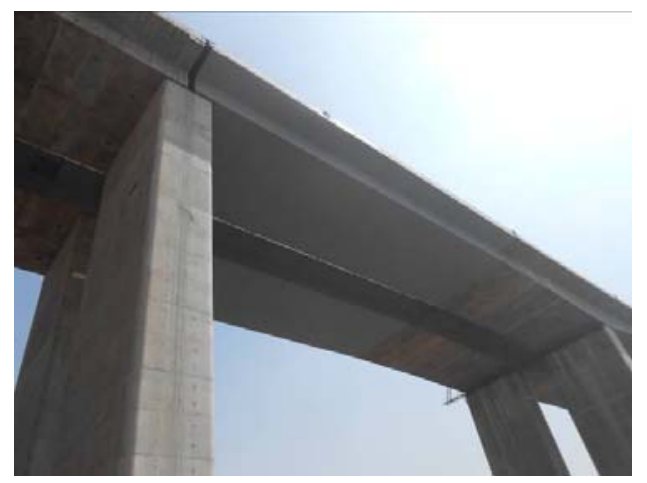

Figure 8. Wei River Freeway Bridge

\subsubsection{Acquisition of stress range spectra}

The photographs of two fatigue details which were studied at the case of Wei River Freeway Bridge are shown in Figure 9. The strain gauge 7-C1001 is at the end of rib-to-diaphragm in a diaphragm. The strain gauge M-D901 is at the weld joint of rib-to-deck in a deck plate. The dynamic stresses, the number and type of trucks were recorded. The rain-flow counting procedure was used to count the different stress ranges.

However, Wei River Freeway Bridge is a part of a new freeway open to traffic since December, 2011. This newly built freeway is planned to have more branches, but at this stage it just connect $\mathrm{Xi}$ 'an city and Tongchuan city. Meanwhile, there is an old in-service freeway nearby, and the old one has more branches and cheaper tolls. Thus, the traffic volume of the new freeway is relatively small at present, and the average daily truck volume is about 500 . 


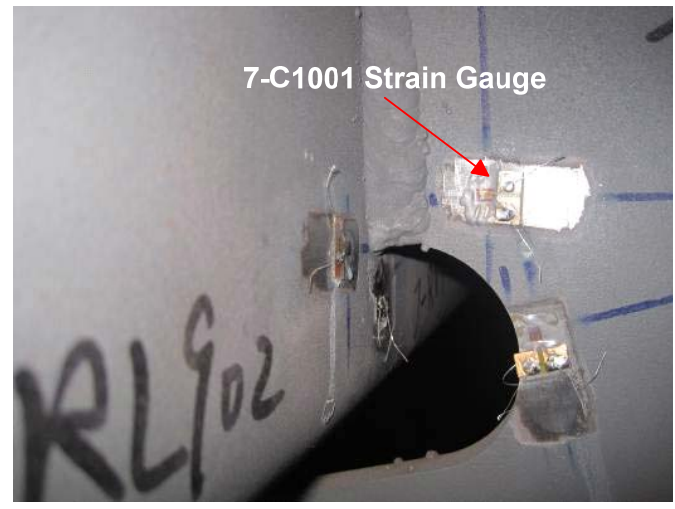

(a) 7-C1001

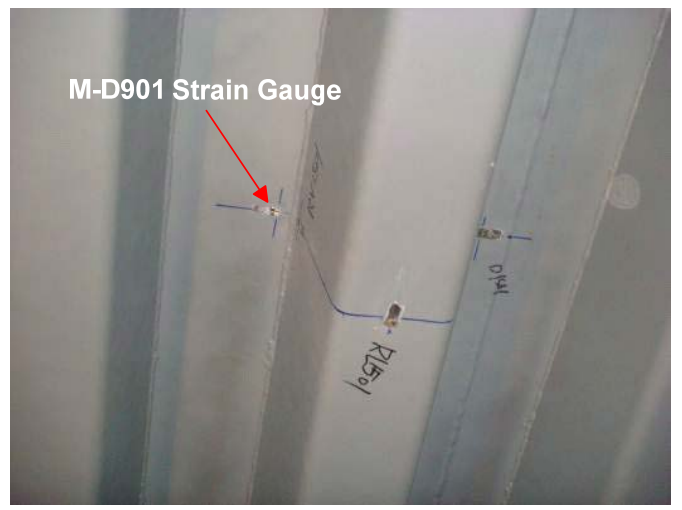

(b) M-D901

Figure 9. Strain Measure Points of Wei River Freeway Bridge

The resulting live load stress range spectra at strain measure points 7-C1001 and M-D901 are given in Figure 10. The maximum stress ranges at $7-\mathrm{C} 1001$ and $\mathrm{M}-\mathrm{D} 901$ are $78 \mathrm{MPa}$ and $57 \mathrm{MPa}$, respectively.

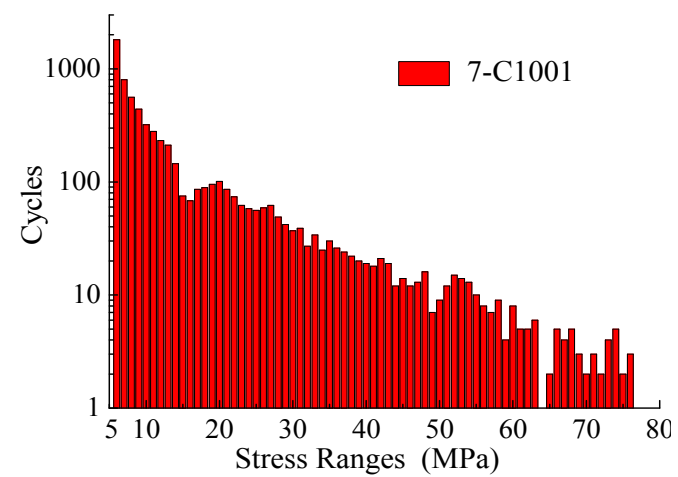

(a) Stress Spectrum of 7-C1001

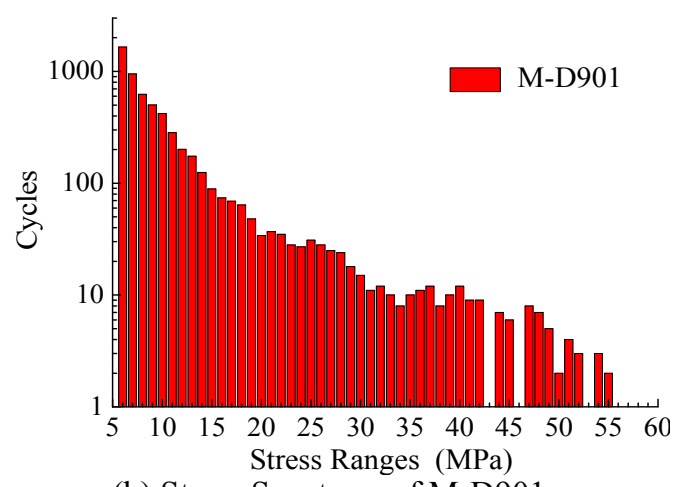

(b) Stress Spectrum of M-D901

Figure 10. Recorded Stress Spectra of 7-C1001 and M-D901

\subsubsection{Fatigue life evaluation}

The estimated fatigue lives for the details in Figure 9 are calculated using Eq. 13, Eq. 15 and Eq. 17 for $N_{3}, N_{34}$ and $N_{4}$, and, respectively. The corresponding life $L_{3}, L_{34}$ and $L_{4}$ are listed and compared in Table 4.

Table 4. Comparison of Estimated Fatigue Life

\begin{tabular}{cccccccccc}
\hline Detail & Category & $N_{3}$ & $L_{3}$ & $N_{34}$ & $L_{34}$ & $N_{4}$ & $L_{4}$ & $\frac{L_{34}-L_{3}}{L_{3}}$ & $\frac{L_{4}-L_{34}}{L_{34}}$ \\
\hline 7-C1001 & $\mathrm{C}$ & 21.0 & 93 & 29.7 & 131 & 29.3 & 129 & $40.9 \%$ & $-1.5 \%$ \\
M-D901 & $\mathrm{D}$ & 22.6 & 118 & 29.5 & 154 & 28.8 & 151 & $30.5 \%$ & $-1.9 \%$ \\
\hline
\end{tabular}

At 7-C1001, the increase in estimated fatigue life between using a single-slope S-N curve and the bi-linear curve is $131-93=38$ years. The ratio of the increased life $\left(L_{34}-L_{3}\right) / L_{3}$ is $40.9 \%$. At M-D901, the ratio of $\left(L_{34}-L_{3}\right) / L_{3}$ is $30.5 \%$. It is also proved that the evaluation based on bi-linear fatigue S-N curves with different slopes above and below the CAFL will predict a longer fatigue life compared to that based on the single slope AASHTO S-N curves. In addition, compared 
to single slope of -4 , the decreased life ratio of the bi-linear S-N curve approach $\left(L_{4}-L_{34}\right) / L_{34}$ is $-1.5 \%$ and $-1.9 \%$.

To examine the proposed bi-linear S-N curves for Eurocode 3, the estimated fatigue lives for 7-C1001 and M-D901 are calculated using Eq. 19 for $N_{35}$. The corresponding $L_{35}$ is compared with $L_{\text {euro }}$ and $L_{34}$ in Table 5. From Table 5, it is obvious that the estimated fatigue life by using bi-linear curves with slopes of -3 and $-5\left(L_{35}\right)$ is longer than by using the suggested bi-linear S-N curves for $\operatorname{AASHTO}\left(L_{34}\right)$.

Table 5. Comparison of Estimated Fatigue Life

\begin{tabular}{|c|c|c|c|c|c|c|}
\hline Detail & Category & $\begin{array}{c}L_{35} \\
\text { (Year) }\end{array}$ & $\begin{array}{c}L_{\text {euro }} \\
\text { (Year) }\end{array}$ & $\begin{array}{c}L_{34} \\
\text { (Year) }\end{array}$ & $\frac{L_{35}-L_{\text {euro }}}{L_{\text {euro }}}$ & $\frac{L_{35}-L_{34}}{L_{34}}$ \\
\hline 7-C1001 & $\mathrm{C}$ & 170 & 162 & 131 & $4.9 \%$ & $29.8 \%$ \\
\hline M-D901 & D & 189 & 201 & 154 & $-6.0 \%$ & $22.7 \%$ \\
\hline
\end{tabular}

\section{SUMMARY AND CONCLUSIONS}

This paper provides information for fatigue life evaluation of in-service steel bridges by integrating field-measured live-load stresses into the bi-linear S-N curves with a break at the constant amplitude fatigue limit (CAFL). The current procedure of AASHTO specifications, with a direct extension of S-N curves to below the CAFL, appears to be too conservative. The slopes of suggested bi-linear S-N curves for the AASHTO specifications are -3 and -4 , while for the Eurocode are -3 and -5 . Equations for the calculation of the equivalent constant amplitude stress range are presented and applied.

From this study, the following conclusions can be drawn:

(1) Compared to the estimated fatigue life using the current single-slope AASHTO S-N curves, applying the bi-linear S-N curves always results in a longer fatigue life for the structural details in a bridge.

(2) When the majority of stress range cycles in a stress spectrum are below the CAFL, the calculated fatigue life by using only the portion of S-N curves below the CAFL can be close to that by using bi-linear curves.

(3) The estimated fatigue life by using the suggested procedure for the bi-linear Eurocode S-N curves is always longer than that by using the suggested bi-linear S-N curves for AASHTO. This is due to the difference in slope below the CAFL.

(4) There are only limited data of long time or high cycle fatigue damage due to variable stresses. Development of such data is recommended.

\section{ACKNOWLEDGMENTS}

The writer gratefully acknowledges the financial support provided by National Natural Science Foundation of China (Grant No.51078039), the Major State Basic Research Development program of China (973 Program) Sub-program (2015CB057703, 2015CB057706), the Special Fund for Basic Scientific Research of Central Colleges of the P.R. China, Chang'an University 
(10821153501, 310821153401, 310821153314 and 2013G3212002), the Applied Basic Research Program of the Ministry of Transport of the P.R. China (2014319812080) and the technical support provided by Xi' an Railway Bureau for the field measurements.

\section{REFERENCES}

[1] AASHTO, "AASHTO LRFD Bridge Design Specifications 5th Ed.", AASHTO, Washington, DC., USA, 2010.

[2] AASHTO, “AASHTO Manual for Bridge Evaluation”, AASHTO, Washington, DC., USA, 2008.

[3] Yen, B.T., Hodgson, I.C., Zhou, Y. E. and Crudele, B.B., "Estimation of Fatigue Life Below CAFL", Proceeding of the 2nd International Conference on Fatigue and Fracture in the Infrastructure, ATLSS Engineering Research Center, Lehigh University, Bethlehem, USA, 2009.

[4] Connor, R.J., Hodgson, I.C., Mahmoud, H.N. and Bowman, C.A., "Field Testing and Fatigue Evaluation of the I-79 Neville Island Bridge over the Ohio River", Center for Advanced Technology for Large Structural Systems (ATLSS), Lehigh University, Bethlehem, USA, 2005.

[5] Crudele, B.B. and Yen, B.T., "Analytical Examination of S-N Curves Below Constant Amplitude Fatigue Limit", Proceeding of the 1st International Conference on Fatigue and Fracture in the Infrastructure, ATLSS Engineering Research Center, Lehigh University, Bethlehem, PA, USA, 2006.

[6] Kwon, K., Frangopol, D.M. and Soliman, M., "Probabilistic Fatigue Life Estimation of Steel Bridges by Using a Bilinear S-N Approach", Journal of Bridge Engineering, ASCE, 2012, Vol.17, No.1, pp. 58-70.

[7] Barsom, J.M. and Rolfe, S.T., "Fracture and Fatigue Control in Structures: Applications of Fracture Mechanics, Third Edition", American Society for Testing and Materials, West Conshohocken, USA, 1999.

[8] Xiang, Y.B., Lu, Z.Z. and Liu, Y.M., "Crack Growth-based Fatigue Life Prediction Using an Equivalent Initial Flaw Model. Part I: Uniaxial Loading”, International Journal of Fatigue. 2010, Vol.32, No.2, pp. 341-349.

[9] Lu, Z.Z., Xiang, Y.B. and Liu, Y.M., "Crack Growth-based Fatigue Life Prediction Using an Equivalent Initial Flaw Model. Part II: Multiaxial Loading", International Journal of Fatigue. 2010, Vol.32, No.2, pp. 376-381.

[10] Fisher, J.W., Nussbaumer, A., Keating, P.B. and Yen, B.T., "Resistance of Welded Details under Variable Amplitude Long-life Fatigue Loading", National Cooperative Highway Research Program (NCHRP), Rep. No. 354, Transportation Research Board, National Research Council, Washington, DC., USA, 1993.

[11] Haibach, E., "Modified Linear Damage Accumulation Hypothesis Accounting for a Decreasing Fatigue Strength During Increasing Fatigue Damage", Laboratorium fur Betriebsfestigkeit, Darmstadt, 1970.

[12] Haibach, E., "Questions Concerning the Fatigue Strength of Welded Joints Considered from a Conventional and a Fracture Mechanical Point of View", Schw. Schn., 1977, No.4, pp. 140-142.

[13] EN 1993-2, "Eurocode 3: Design of Steel Structures: Part 2: Steel Bridges", European Committee for Standardization, Brussels, 2006.

[14] Schilling, C.G., Klippstein, K.H., Barsom, J.M., et al., "Fatigue of Welded Steel Bridge Members under Variable Amplitude Loading”, National Cooperative Highway Research Program (NCHRP), Rep. No. 188, Transportation Research Board, National Research Council, Washington, DC., USA, 1978. 
[15] Yen, B.T., Hodgson, I.C., Zhou, Y.E. and Crudele, B.B., "Bi-linear S-N Curves and Equivalent Stress Ranges for Fatigue Life Estimation", Journal of Bridge Engineering, ASCE, 2013, Vol. 18, No.1, pp.26-30.

[16] Wang, C.S. Yan, S.L. and Hao, L., "Fatigue Safety Assessment of Existing Railway Steel Bridges Based on In-situ Monitoring Data", Proceeding of the 6th International Conference on Maintenance, Safety and Management, Italy, 2012, pp. 812-817.

[17] Partov, D., and Dinev, D., "Structure, Design and Construction of a Steel Orthotropic Bridge in Sofia ", Advanced Steel Construction, 2007, Vol. 3, No. 4, pp. 752-764. 